\title{
Experiences of Family Caregivers of Stroke Patients Admitted in Rehabilitation Hospitals
}

\author{
Joo-Hee Bae ${ }^{1)}$, Hyo-Jeong Kang ${ }^{2) *}$, Nam-Hee Kim \\ 재활전문병원에 입원한 뇌졸중 환자의 가족 돌봄 제공자 \\ 돌봄경험 \\ 배주희1), 강효정2)*, 김남희3)
}

\begin{abstract}
The study is a phenomenological study to investigate the essence and meaning of family caregiver for experiences of stroke patients admitted to rehabilitation hospitals. For this purpose, Colaizzl's phenomenological research methods was applied with six participants who participated in care of stroke patients admitted to rehabilitation hospitals. It is a study using data collection through in-depth interviews to describe caregiver of stroke patients experiences in detail and categorizes them by subject. The results of the study are as follows. Sixteen themes, six cluster, and three category were organized totally. In 'negative changes in my life' category, there are two clusters: 'a life trapped in the wheel', and 'lost myself'. In 'caring pressure' category, there are two clusters: 'realistic caring burden', and 'psychological caring burden'. In 'the stem of hope' category, there are two clusters: 'heart towards patients', and 'motivation of hope'. Caregivers are suffering, handling difficulties, and trying to find hope in their life. Therefore, substantial and continuous supports and resources will be needed by caregivers of stroke patients admitted to a rehabilitation hospital.
\end{abstract}

Keywords: Colaizzl's Phenomenological Research, Stroke, Rehabilitation Hospitals, Caregivers, Experiences

Received(June 7, 2020), Review Result(1st: July 28, 2020, 2nd: September 17, 2020), Accepted(October 28, 2020)

1) (Associate Professor) 47011 Dept. Nursing, Kyungnam College of Information \& Technology, 45 Jurye-ro, Sasang-gu, Busan, Korea

email: baejh@eagle.kit.ac.kr

2) (Associate Professor, Corresponding Author) 47230 Dept. Nursing, Dong-Eui Institude of Sience and Technology of nursing, Busan, Korea

email: kanghj@dit.ac.kr

3) (Rearcher) 49267 Research Institute of Wholistic Nursing Science, 262, Gamcheon-ro, Seo-gu, Busan, Korea email: saenomi@hanmail.net 
요 약

본 연구의 목적은 재활전문병원에 입원한 뇌졸중 환자의 가족 돌봄 제공자의 경험에 대한 의미와 본 질을 파악하기 위하여 시도된 현상학적 연구이다. 재활전문병원에 입원한 뇌졸중 환자 돌봄에 참여하 는 가족 돌봄 제공자 6 명을 대상으로 Colaizzl의 현상학적 연구 방법을 적용하였다. 심층 면담을 통하 여 자료수집을 하였고, 이를 주제에 따라 범주화하였다. 이 연구의 결과는 다음과 같다. 대상자의 돌 봄 경험에 관해 도출된 주제는 총 16 개, 주제 모음은 6 개, 범주는 3 개로 구조화되었다. 최종 도출된 범주와 주제 모음은 '내 삶의 부정적 변화'의 범주에서 '쳇바퀴에 갇힌 인생', '잃어버린 나 자신'의 2 개의 주제 모음이 도출되었으며, '돌봄 부담감의 범주에서 '현실적 돌봄 부담감, '심리적 돌봄 부담감 '의 2 개의 주제 모음이 도출되었으며, '희망의 줄기'의 범주에서는 '환자로 향하는 마음', '희망의 동기 '의 2 개의 주제 모음이 도출되었다. 대상자는 환자를 돌보면서 여러 가지 어려움을 겪고, 감당해 나가 고 있었으며, 이런 생활 속에서 희망을 품으려 노력하고 있었다. 따라서 재활전문병원에 입원한 뇌졸 중 환자의 가족 돌봄 제공자를 돕기 위한 실질적이고 지속적인 사회적 지지와 자원이 필요할 것이다.

핵심어: 현상학, 뇌졸중, 재활전문병원, 가족 돌봄 제공자, 경험

\section{1. 서론}

\section{1 연구 배경}

뇌졸중은 현재 국내 사망원인 중 3 위로 사망률은 감소하는 추세지만 유병률은 증가하고 있다[1]. 또한 의학의 발전과 더불어 발병 후 생존 가능성이 증가하여 뇌졸중 생존자들에 대한 치료와 간호 가 더욱 중요해지고 있다[2]. 뇌졸중은 급성기 치료가 종료된 이후에도 편마비, 감각 손상, 인지장 애, 지각장애, 연하장애 등과 같은 후유장해로 지속적이고 체계적인 재활치료와 건강관리가 필요하 다[3][4]. 보건복지부는 재활을 중점으로 하는 병동과 전문병원의 신설을 증대하고 있다[5].

뇌졸중 환자는 후유장해로 일시적 또는 영구적인 기능 상실을 가져와 일상생활 동작을 스스로 할 수 없게 되고, 타인에게 의존적인 생활을 하게 된다[6]. 전통적으로 효를 중요시하며 가족 문화 가 중요한 우리나라에서는 뇌졸중 환자의 $70.7 \%$ 가 가족의 돌봄을 받고 있다[7].

뇌졸중은 장기적인 관찰과 돌봄이 필요하며, 치료 진행 과정과 앞으로의 예후를 예측하기 어렵 다. 가족들은 환자를 돌봄으로써 신체적 부담감을 비롯해 심리적 건강 상태의 적신호도 함께 발생 하게 된다[8][9]. 그리고 재활전문병원의 뇌졸중 환자 가족 돌봄 제공자는 많은 시간과 희생을 요구 하기 때문에 급성기 뇌졸중 환자를 돌보는 가족 돌봄 제공자 보다 스트레스의 정도가 더 높다[10].

재활전문병원에 입원 중인 뇌졸중 환자 가족 돌봄 제공자는 장기간의 회복기 동안 다양한 의료 의 장벽을 경험하게 되고, 이를 해결하기 위해서는 그들이 접근 가능한 사회복지 제도에 대한 이 해 및 자원 연계를 위한 지원 체계가 필요하다. 또한 재가 간호를 위해 의료진과 함께 퇴원계획을 준비하여 성공적인 지역사회 재통합을 위해 적극적으로 참여해야 한다[11]. 특히 회복기 과정의 가 족 돌봄 제공자에게는 뇌졸중 환자 회복의 연속선상에서 다학제간 팀을 통한 협력 지원이 필요하 다[12].

만성질환인 뇌졸중 환자를 돌보는 가족 돌봄 제공자의 돌봄에 관한 선행연구[8-10]를 살펴보면 
대부분 양적연구로 가족 돌봄 제공자의 사회적 및 심리적 상태와 다양한 문제들을 포괄적으로 이 해하는 것에 제한점이 있다. 따라서 가족 돌봄 제공자의 돌봄 경험에 대한 심층적인 연구가 필요 하다. 이에 본 연구는 재활전문병원 뇌졸중 환자의 가족 돌봄 제공자가 경험하는 돌봄 경험의 구 조와 본질을 Colaizzi의 방법론을 통해 규명하고자 한다. 이에 그들의 주관적 경험과 관점을 파악 하고 기술함으로써 주 돌봄 제공자의 삶의 질을 향상하는 간호 중재 연구의 기초자료를 제공하고 자 한다.

\section{2 연구 목적}

본 연구는 현상학적 접근을 통해 재활전문병원 뇌졸중 환자 가족 돌봄 제공자의 돌봄 경험의 의미 와 본질을 참여자의 관점에서 심층적으로 이해하고 기술하는 것이다. 본 연구의 연구 질문은 “재 활전문병원에 입원한 뇌졸중 환자의 가족 돌봄 제공자 경험의 본질은 무엇인가?"이다.

\section{2. 연구방법}

\section{1 연구설계}

본 연구는 Colaizzi[13]의 현상학적 연구 방법을 이용하여 재활전문병원에 입원하고 있는 뇌졸중 환자의 가족 돌봄 제공자의 경험 의미 및 본질을 탐구하고자 하였다. Colaizzi의 분석 방법은 연구 대상자의 전체에서 나타나는 의미와 주제를 추출하고, 도출된 구조 속에서 구성 요소 간의 관계를 설정하면서 일관성 있는 진술로 통합해 나간다는 점에서 뇌졸중 환자 가족 돌봄 제공자의 경험에 대한 본질을 파악하고자 하는 본 연구에 적합한 방법이라 할 수 있다.

\section{2 연구 대상 및 자료수집}

본 연구에서는 재활전문병원에 입원 중인 뇌졸중 환자의 가족 돌봄 제공자의 돌봄 경험 본질을 탐 색하기 위해 다음과 같이 대상자를 선정하였다.

첫째, 재활전문병원에 입원 중인 뇌졸중 환자의 가족 돌봄 제공자

둘째, 최소 3 개월 이상 환자를 돌봐온 가족 돌봄 제공자

셋째, 하루에 6시간 이상 뇌졸중 환자를 돌보는 가족 돌봄 제공자

본 연구의 대상자는 연구 선정조건에 적합하고, 연구의 취지를 이해하고 동의한 6명을 대상으로 하였다. 참여자의 평균연령은 61.8 세, 남성 2 명, 여성 4 명, 평균 돌봄 기간 9.2 개월, 평균 하루 돌봄 시간 15.8 시간, 돌봄 교대 자는 0.7 명이었다[표 1].

자료수집은 심층 면담 방법을 활용하였으며, 2018년 6월부터 9월까지 자료가 포화할 때까지 진 


\section{Experiences of Family Caregivers of Stroke Patients Admitted in Rehabilitation Hospitals}

행하였다. 자료수집을 위해 해당 재활전문병원 간호부서의 담당자, 담당 수간호사와 담당 주치의에 게 연구목적을 설명하고 협조를 구하였다. 자료수집은 연구자들이 참여자와의 사전 만남을 통해 면담 전 신뢰 관계를 형성하여 심층 면담이 이루어질 수 있도록 준비한 후 진행하였다. 면담 장소 는 서로의 대화가 방해받지 않으며, 조용하고 부드러운 분위기에서 편안한 마음으로 면담이 이루 어질 수 있도록 했다. 면담 시간은 돌봄 제공을 도와줄 수 있는 다른 가족이 가능한 시간을 사전 에 약속하여 진행하였고, 면담 시간은 최소 30 분에서 최대 2 시간 이내로 시행하였다. 면담은 한 사 람에게 새로운 자료나 정보가 나오지 않아 자료가 포화할 때까지 진행하였고, 추가 면담을 포함하 여 참여자마다 1 3회의 면담이 이루어졌다.

면담은 일상적인 대화로부터 시작하여 참여자가 편안하게 진술하도록 유도하였으며, 주 질문으 로 시작하여 필요하면 보조 질문을 사용하여 참여자가 자신의 경험을 충분히 이야기할 수 있도록 하였다. 면담 시 사용된 주 질문은 "뇌졸중 환자를 돌보면서 겪은 어려움은 무엇입니까", "환자에 대한 감정은 어떠합니까?", "간호하는 자신에 대해서 스스로 어떻게 생각합니까?" "미래에 대한 생각은 어떠합니까?” 등이다. 면담 내용은 참여자에 동의하에 음성녹음을 하였으며, 녹음한 것은 당일 참여자의 언어 그대로 필사하였다. 또한, 면담 상황이나 참여자의 언어적, 비언어적 표현도 메모 노트에 기록하여 분석에 참고하였다. 참여자의 일반적인 사항은 첫 면담 시작 전 준비된 간 단한 문항의 설문지를 본 연구자가 직접 읽어주고 참여자의 응답을 기재하는 방식으로 조사하였 다.

\section{3 연구의 신뢰도와 타당성}

연구의 신뢰도와 타당도를 높이기 위하여 네 가지 기준에 부합되도록 하였다. 첫째, 사실적 가치로 신뢰성 확보를 위해 모든 참여자의 면담을 녹음하고 진술 그대로 필사하였다. 그리고 대상자와 신 뢰 관계를 형성한 후 면담을 시행하였고. 환자를 돌보는 사람을 확보한 후 독립되고 조용한 공간 에서 시행하여 대상자가 충분히 솔직하게 표현할 수 있는 환경을 조성하였다. 둘째, 적용성을 확보 하기 위해 중복되는 내용이 나올 때까지 대화를 진행하였으며, 대상자를 선정할 때 구체적인 선정 기준을 정하여 선정하였다. 셋째, 일관성을 유지하기 위해 3 명의 연구자가 각각 주제들을 도출한 후 합의하는 과정인 연구자 삼각 검증 과정을 거치고, 분석된 결과에 대해 2 명의 참여자 피드백을 거쳐 수정하는 절차를 거쳤다. 넷째, 중립성 확보를 위해 연구 대상자는 환자 보호자와 의료인으로 만난 관계만 선정하여, 편견을 최소화되고 참여자의 관점을 최대한 드러나도록 함으로써 중립성 있는 결과를 도출하려고 하였다. 
[표 1] 대상자의 일반적 특성

[Table 1] The General Characteristic of Participants

\begin{tabular}{|c|c|c|c|c|c|c|}
\hline Participants & Age & Sex & $\begin{array}{c}\text { the period of } \\
\text { care } \\
\text { (month) }\end{array}$ & $\begin{array}{c}\text { a day's care time } \\
\text { (hour) }\end{array}$ & $\begin{array}{c}\text { the relation of a } \\
\text { patient }\end{array}$ & $\begin{array}{c}\text { Another } \\
\text { Caregiver }\end{array}$ \\
\hline \hline 1 & 52 & Female & 12 & 24 & Wife & 0 \\
\hline 2 & 67 & Male & 7 & 7 & Husband & 2 \\
\hline 3 & 54 & Femal & 15 & 10 & Wife & 1 \\
\hline 4 & 61 & Femal & 9 & 24 & Wife & 0 \\
\hline 5 & 59 & male & 8 & 6 & Husband & 1 \\
\hline 6 & 68 & Femal & 4 & 24 & Wife & 0 \\
\hline
\end{tabular}

\section{4 자료분석}

본 연구에서 자료분석은 Colaizz[13]가 제시한 현상학적 접근방법을 근거로 다음의 절차를 따라 분 석하였다.

제 1 단계는 모든 참여자의 구두 혹은 문자로 된 내용을 듣거나 읽고 그들의 경험에 대한 느낌을 얻기 위해 면담 상황을 떠올리면서 면담 녹음내용을 들으면서 진술 그대로 필사하였고, 필사본을 반복적으로 읽어 전체적인 느낌을 얻었다.

제 2 단계는 현상에 직접적으로 관련된 의미 있는 진술을 추출하기 위해 세 연구자가 참여자의 경험의 본질적인 의미를 나타내고 있다고 판단되는 부분이나 참여자들 간에 반복적으로 진술되는 내용에서 강조되는 부분을 추출하였다.

제3단계는 추출된 주요 진술 또는 구절들로부터 의미를 도출하였다.

제 4 단계는 각각의 맥락 속에 숨겨진 의미를 주제로 구성하고, 구성된 주제는 한 단계 더 추상적 인 주제 모음으로 구성하였다. 구성된 의미는 세 연구자가 함께 확인하고 공통된 의미를 중심으로 하여 연구자의 의미로 통합하였다.

제5단계는 도출된 의미를 주제로 묶고, 주제를 묶어 주제 모음으로 조직하고, 주제 모음을 묶어, 범주로 구조화하였다.

제6단계는 대상자의 돌봄 경험의 구조와 본질이 확인된 주제, 주제 모음, 범주를 현상학적 본질 적인 구조에 대한 진술로 최종 기술하였다.

제7단계는 분석 결과의 타당성을 확보하기 위해 연구 참여자 2인과 현재 재활전문병동에 입원 한 뇌졸중 환자 돌봄 가족원 2인에게 타당화를 확인하였다.

\section{5 윤리적 고려}

본 연구는 연구 참여자의 보호를 위하여 연구 시작 전 연구의 목적과 과정을 자세하게 설명한 뒤, 자발적으로 연구에 참여하고, 참여 동의서를 작성한 대상자를 연구 참여자로 선정하였다. 면담 시 작 전에는 비밀보장과 익명성, 원할 경우 자유롭게 면담을 중지하거나, 면담에 응하지 않아도 된다 
는 사실을 다시 확인시키고, 참여자가 동의할 때만 면담의 내용은 녹음할 것을 알렸다. 또한, 본 연구 과정 중 알게 된 면담 내용은 연구목적으로만 사용할 것임을 설명하였다. 참여자들의 동의하 에 녹취된 면담내용은 마이크로소프트 워드를 이용하여 입력하되, 참여자의 신원이 드러나지 않도 록 신원과 관련된 개인정보는 모두 삭제하고 별도의 고유번호를 부여하여 익명 처리하였다.

\section{3. 연구결과}

재활전문병원에 입원한 뇌졸중 환자의 가족 돌봄 제공자 돌봄 경험은 16 개의 주제, 6 개의 주제 모 음, 3개의 범주로 도출되었다[표 2].

\section{1 삶의 부정적 변화}

대상자의 첫 번째 범주로 '쳇바퀴에 갇힌 인생' '잃어버린 나 자신'의 2 개의 주제 모음이 도출되었 다.

\subsection{1 쳇바퀴에 갇힌 인생}

환자 옆에서 손과 발이 되어 되어주며, 환자 옆을 지키고 있으면서, 병원에 갇힌 채 되풀이되는 일 상 속에 살아가며 힘들어하고 있었다.

\section{비울수 없는 자리}

잠깐도 못 비워요. 그래서 아직 바다 구경도 한번 못 갔어요. 쓰러지고 수술받고 그러니깐 남편 이 아무것도 혼자 못해요. 걷지도 못하고, 밥도 못 먹고, 대소변도 눕혀서 받아내야 하는데, 자리를 어찌 비워요(참여자 1 ).

지난번에 잠깐 마트 갔다 온다고 자리 비웠다가 남편이 침대에서 떨어져서 얼마나 난리가 났 었다고요. 그래서 잠시라고 혼자 못 놔두고 가요. 화장실 갈 때도 옆에 부탁하고 가요(참여자 4).

\section{반복되는 일상}

맨날 똑같이 발전되는 거 없이 밥 먹고, 치료 가고, 자고요. 다른 생활이 있겠어요(참여자 6).

일하고 병원으로 바로 와서 간병인이랑 교대해줘야죠. 일하고 병원에서 자고, 일어나서 일하고 다시 병원 오고 그럽니다(참여자 5).

맨날 병원에 있으니 병원 스케줄대로 돌아가죠. 특별한 일 없이 하루하루가 지나가죠(참여자 4).

\subsection{2 잃어버린 나 자신}

자신의 인생 없이 병원에서 많은 시간을 보내며, 자신을 위해서 쓸 수 있는 시간도 없었으며, 환자 를 돌보면서 신체적 질환도 겪고 있었다. 


\section{외적 미의 포기}

옛날에는 그래도 한 몸매 했는데, 신랑 쓰러지고 나서 그때부터 딱 손 놓고, 그날 이후로 화장 도 한번 안 해 봤어요(참여자 1 ).

아내가 건강할 때는 같이 운동도 하고 머리 염색도 했는데, 지금은 염색 안 한 지 오래되었어요. 아내가 저렇게 누워있는데 혼자 염색해서 무엇 하겠어요(참여자 2).

화장한 손, 로션 바른 손으로 신랑 못 만지잖아요. 미끄러워서 로션도 안 바르고, 발라도 금방 비누로 씻어 버리고, 항상 그렇게 합니다(참여자 6).

\section{사회생활의 제한}

친구들 만나서 수다 떨고 모임도 하고 또 우리 신랑 따라서 산에도 가고, 교회 다니고 그랬는데, 이제 아무것도 일절 안되는 거죠(참여자 4 ).

바깥세상하고 단절되어 있어요. 사람들을 만날 때 눈을 똑바로 못 쳐다보겠고, 친구들도 못 만 나겠어요. 만나면 자존심 상하고, 나의 애기를 남한테 자꾸 하는 것도 싫어요(참여자3).

친구들하고 술 한잔하는 거 꿈도 못 꾸죠. 집안도 엉망인데 집 안 청소할 시간도 없어요(참여자 5).

\section{신체 증상의 고통}

제 무릎도 이쪽저쪽 아프고 안 아픈 데 없고, 무릎대 발목대 팔꿈치대 이런 거 다 사놨어요. 아플 때 주사도 맞고, 어깨 같은 곳은 근육 이완제 이런 거 먹고, 파스 같은 거 사놓고, 해열제 늘 사놓고, 머리 아프고 목 아프면 바로 먹고, 여기저기 쑤시면 바로바로 먹고, 해열진통제는 아예 재 어 놓고 먹고, 근육통제 같은 것도 엄청나게 사놨어요. 저 안에 가보면 약국입니다. 제가 먹으려고 다 사놓았어요(참여자1)

저도 4년 전에 위암 수술했어요. 음식 가려먹고 해야 하는데 그럴 수가 있나요. 제때제때 식사 를 못 해서 속 쓰릴 때도 있고 그러네요(참여자2).

\section{2 돌봄 부담감}

대상자의 두 번째 범주로 '현실적인 돌봄 부담감' '심리적 돌봄 부담감'의 2개의 주제 모음이 도출 되었다.

\subsection{1 현실적 돌봄 부담감}

환자를 돌보면서 부족한 간호술로 간호하는 데 어려움을 느끼고 있었으며, 경제적인 도움과 가족 의 도움이 부족하였다. 그리고 병원의 공동생활로 인해 불편함을 겪고 있었다. 


\section{Experiences of Family Caregivers of Stroke Patients Admitted in Rehabilitation Hospitals}

\section{부족한 전문적 기술}

제가 가래 빼는 거 잘하고 있다고 생각하고 있었어요. 그런데, 제가 깊이 넣어서 피 나고 그랬 어요. 그때 제가 우리 남편을 잘못 간호했나 그런 생각이 들더라고요. 저렇게 눕혀 놓고, 오른쪽은 제가 잘못 만지니깐 마비상태가 계속되는 것인지, 제가 못 하는 것이 많죠(참여자3).

변 기회를 딱 놓쳐 버리면 변비가 되고 그러더라고요, 제가 남자라 그런지 제대로 잘하지 못해 요. 그리고 제대로 배운 적도 없어요(참여자2).

\section{부족한 도움}

남편 쓰러지고 돈 벌어오는 사람이 없어요. 자식들 아직 대학생인데 자기 생활비밖에 못 벌어요. 그래서 있던 돈 다 쓰고, 집 하나 대출받아 놓고, 앞으로 막막하죠(참여자1).

연금 받고 사는데 치료비로도 연금 모자라요. 그래서 간병인도 못 써요. 애들한테 미안해서 경 제적 도움 바라지도 못하고 있어요(참여자6).

혼자 돌봐요. 우리 남편은 여기 오시는 봉사자들이 할 수 있는 부분이 아니라서 도움받는 것이 어려워요. 의료인 아니면 누가 이런 간호를 할 수 있겠어요. 우리 애들한테도 남편 못 맡기죠. 사 실 애들한테 부담 주는 것도 힘들어요. 혼자 짊어지고 있죠(참여자4).

\section{견뎌야 하는 공동생활}

옆에 아줌마는 눈만 뜨면 말을 너무 많이 해요. 그거는 저한테 완전 소음이거든요. 전화 소리도 너무 크게 해놓고, 통화할 때 목소리도 커서, 잠깐 낮잠 잘 때 깜짝 놀라서 제대로 쉴 수가 없어요 (참여자 3).

서로 자리 차지 많이 하려고 싸울 때도 있어요. 서로 자리 편한 침대차지 하려고, 병동에 가서 환자 빠지면 먼저 해달라고 선착순 해놓기도 해요. 그리고 짐들이 너무 많아서 놔둘 곳도 없고 병 실 안이 정리가 안 돼요(참여자 6).

샤워하려고 마음대로 벗고 다닐 수도 없고, 잘 때 코 고는 사람들이 있어 편히 잠을 잘 수도 없 고, 병실에서 환자 냄새, 음식 냄새가 섞여서 냄새 참기도 힘들어요(참여자1).

\subsection{2 심리적 돌봄 부담감}

환자를 돌보면서 심적으로 지쳐가고 있었다. 삶의 회의감도 느끼면서, 인생을 살아가는 이유를 찾 기 힘들어하였다. 그리고 어두운 미래에 대한 절망감을 표현하면서 삶의 포기를 원하기도 하였다.

\section{지쳐가는 마음}

스트레스가 너무너무 심해서, 어쩔 땐 죽고 싶은 마음도 들어요. 내가 무슨 죄를 지어서 이렇게 살고 있는지 모르겠어요(참여자4).

저도 아프지, 아내도 아프지, 다 늙어서 이게 뭐 하는 짓인가 싶기도 하죠. 사람은 말년이 행복 
해야 한다는데 사는 이유를 모르겠어요(참여자2).

\section{어두운 미래의 절망감}

우리 남편이 언제 좋아지는지 모르잖아요. 이렇게 계속 갈 수도 있고, 뚜렷한 회복 시기가 없으 니깐 희망도 없어지고. 미래가 안 보여요. 아예 기대를 안 하고 살아요. 살길이 막막할 때가 있어 요(참여자 5).

우리 애들 결혼시키고 나서 내 손으로 이 사람 죽이고 나도 죽자. 이런 생각까지 하고 있어요. 집에 무서워서 못가요. 제가 우리 남편 죽여놓고 저도 죽을 것 같은 자살해 버리고 싶은 충동이 들까 봐요. 죽으면 죽고. 살면 살고. 그런 마음 갖고 있어요(참여자1).

\section{3 희망의 줄기}

대상자의 세 번째 범주로 '환자로 향하는 마음', '희망으로 나아가기'의 2개의 주제 모음이 도출되 었다.

\subsection{1 환자로 향하는 마음}

환자와 함께 있으면서 힘들 때마다 환자와 함께한 추억을 떠올리며 힘든 마음을 이겨내려고 노력 하고 있었으며, 환자에 대한 책임감으로 이겨내고 있었다. 그리고 환자의 손을 잡고, 눈을 마주치 고 대화하면서 서로의 교감을 통해 위로받고 있었다.

\section{환자와 함께한 추억}

우리 남편은 옛날에 제가 먹고 싶은 거 말만 하면 퇴근할 때 꼭 사 왔어요 우리가 연애도 오래 했어요. 너무 듬직했고, 쓰러지기 직전까지 파이팅 하면서 가정에도 직장에서도 열심히 했어요. 그 래서 제가 우리 남편 손을 놓을 수가 없어요(참여자1).

애 엄마가 저 위암 수술했을 때 정말 옆에서 잘해줬어요. 제가 무뚝뚝한 가장이었는데도, 옆에 서 비위 맞춰주고 참 참한 아내였어요. 자식들도 잘 키우고, 쥐꼬리만 한 월급 아끼면서 산다고 얼 마나 아끼면서 가정 살림했는지 몰라요(참여자2).

우리 남편은 너무 성실히 일했어요. 바람 한번 안 피우고, 노름 한번 안 하고, 꼬박꼬박 월급 챙 겨다 주고, 저 아프다고 하면, 약 한 봉지 꼭 챙겨주고 했어요. 우리 친정 식구들한테도 잘하고, 같 이 여행도 많이 갔어요. 남편 쓰러지기 전에 너무 행복했었어요(참여자6).

\section{환자에 대한 책임감}

우리 남편 요양병원에 그냥 놔두면 욕창 생기고, 결국은 죽는 거잖아요. 저는 그렇게는 못 살아 요. 끝까지 남편 간호할 각오로 살 거예요(참여자3).

집사람 인생이 제 인생이죠. 우리 집사람 제가 책임져야지 누가 책임지겠습니까. 지금까지 옆에 


\section{Experiences of Family Caregivers of Stroke Patients Admitted in Rehabilitation Hospitals}

서 고생한 아내이니 이제는 제가 책임지고 우리 아내 지켜내야죠(참여자5).

\section{환자와의 교감}

남편이 말은 잘하지 못해도 가끔 제 눈 보고 눈시울을 붉혀요. 그러면 제가 손 꼭 잡아요. 그러 면 서로 말 안 해도 통하는 게 있어요. 그러면 마음이 풀리고 그래요(참여자1).

반응이 많이 좋아지고 있어. 어깨에 손 쑥 올려서 여기 잡고. 토닥토닥하고 이런다니까요. 표현 해주거든요. 그럼 너무 장하고, 견뎌 내줘서 고맙고 그래요(참여자4).

아내가 고마워해요. 계속 고맙다고 해요. 그리고 제 손을 계속 잡고 싶어 해요. 저도 아내 손 잡 고 있으면, 마음이 편안해져요(참여자5)

\subsection{2 희망의 동기}

어려울 때 가족이 옆에서 힘이 많이 되어주고 있었다. 그리고 신앙으로 지금의 힘든 시간을 견디 고, 지금의 순간도 좋은 것으로 여기려고 노력하였다. 그리고 앞으로의 삶의 목표를 세우며 희망을 다져가고 있음을 발견할 수 있었다.

\section{가족의 사랑}

우리 딸들이 잘해요. 옆에서 큰 힘이 되어줘요. 저 혼자 간호하기 힘들다고 번갈아 가며 엄마를 간호해 줘요. 딸들 아니었으며 정말 힘들었을 거예요(참여자2).

우리 자식들이 힘내라고 계속 문자 줘요. 그리고 저 먹으라고 맛있는 것도 사다 주고요. 아빠 나을 수 있다고 옆에서 힘주고, 자기들은 자기들이 알아서 한다고 걱정하지 말라고 늘 그래요(참여 자1).

양가에서 밑반찬도 많이 해주시고, 주말에는 교대도 해주시고 많이 도와주세요. 가족의 도움이 있으니 힘내서 일도 하고 아내도 간호할 수 있는 거 같아요(참여자5).

제가 많이 울어요. 아들들이 안아줘요. 그리고 엄마 힘든 거 고생하는 거 빨리 돈 벌어서 호강 시켜 줄 테니 조금만 참으라고 힘내라고 해줘요. 애들한테 해준 것도 많이 없는데 효도하겠다는 말 들으면 그렇게 위로가 될 수 없어요(참여자6)

\section{신앙의 믿음}

저는 기독교 믿음이 있어서 마음속으로 항상 기도해요. 하나님이 저와 제 가족을 사랑하시고 지 켜주시리라 믿어요. 지금 이런 상황을 주신 것도 다 하나님의 뜻이 있는 것으로 생각해요. 원망하 지 않고, 감사하며 살려고 합니다(참여자3).

마음을 비우려고 노력합니다. 예전에는 종교가 없었어요. 그런데 이제는 보이는 종교가 있으면 저도 모르게 기도하고 있더라고요. 목사님 설교도 듣고, 스님 설교도 듣고, 그러면 마음이 편해지 더라고요. 얼마 전에 목사님 오셔서 남편을 위해 기도해주시고 가셨어요. 같이 기도하면서 얼마나 
울었는지 몰라요. 그런데 마음이 엄청 가벼워졌어요. 인생은 제 뜻대로 되지 않는 것이었어요. 신 앙이라는 것에 기대어 보니 지금 현실에 대한 부담감이 줄어들었어요. 저를 위해 남편을 위해 우 리 가족을 위해 계속 기도하고 있어요(참여자1).

\section{새로운 삶의 목표}

인생에 별것 없더라고요. 조그만 행복부터 찾아가고 있어요. 남편 손 조금 더 올라가는 거 그거 하나부터 행복을 찾아가고 있어요. 지금 저보다 더 나쁜 상황에 있는 사람들도 있잖아요. 그래도 우리는 치료라도 받고 있으니, 우리가 행복하다고 생각하면서 살려고 해요. 그러다 보면 희망이 생 겨요(참여자4).

애들도 많이 컸고, 우리 부부 인생을 생각하고 살려고 합니다. 우리 집사람 조금 더 좋아지면 같이 가까운 곳부터 여행할 거에요. 여행 가서도 간호 잘할 수 있도록 열심히 배울 거에요(참여자 $5)$.

남편이 조금만 더 걷는 게 익숙해지면, 여기 앞에 공원부터 걸어 볼 거에요. 인생에 가장 소중 한 사람이 우리 남편인 걸 알았어요. 남편한테 바라는 것은 지금보다 조금씩만 더 좋아지는 거고, 여기 공원부터 산책하는 게 목표에요. 둘이서 좋은 바깥 공기 마시고, 맛있는 거 하나씩 사 먹으면 서 오순도순 그렇게 사는 게 꿈이에요(참여자6).

[표 2] 대상자 돌봄 경험의 주제

[Table 2] The Theme of the Participants Care Experience

\begin{tabular}{|c|c|c|}
\hline Category & Theme cluster & Theme \\
\hline \multirow{5}{*}{ Negative changes in my life } & \multirow{2}{*}{ A life trapped in the wheel } & Non-empty seat \\
\hline & & Repeated days \\
\hline & \multirow{3}{*}{ Lost myself } & Abandonment of beaty \\
\hline & & Limits of social life \\
\hline & & Pain of body \\
\hline \multirow{5}{*}{ Caring burden } & \multirow{3}{*}{ Realistic caring burden } & Scarcity of professional skills \\
\hline & & Scarcity of help \\
\hline & & Shaped life \\
\hline & \multirow{2}{*}{ Psychologic caring burden } & Exhausted heart \\
\hline & & Despair of dark future \\
\hline \multirow{6}{*}{ The stem of hope } & \multirow{3}{*}{ Heart towards patients } & Memories with patients \\
\hline & & Responsibilities for patients \\
\hline & & Consensus with patients \\
\hline & \multirow{3}{*}{ Motivation of hope } & Love of family \\
\hline & & Belief of religion \\
\hline & & New target of life \\
\hline
\end{tabular}




\section{4. 논의}

뇌졸중 환자 가족 돌봄 제공자의 돌봄 경험에 대해 살펴봄으로써, 돌봄 경험의 본질과 구성요소를 알아보았다. 가족 돌봄 제공자들은 환자 옆에 상주하며 돌봄의 일상을 반복하고, 쳇바퀴에 갇힌 인 생을 보냈다. 외적 미를 포기하고 사회생활의 제한과 신체적 고통으로 자기 자신을 잃어버리는 삶 의 부정적 변화를 경험하였다. 또한, 환자를 돌봄에 있어 부족한 전문적 기술, 부족한 주위 도움과 견뎌야 하는 공동생활로 현실적 돌봄 부담감을 느끼고 있었다. 지쳐가는 마음과 어두운 미래 대한 절망감으로 심리적 돌봄 부담감도 있었다. 하지만 환자와 함께한 추억, 환자에 대한 책임감, 환자 와의 교감을 통해 환자로 향하는 마음과 가족의 사랑, 신앙의 믿음, 새로운 삶의 목표를 가지게 되 어 희망의 동기를 경험하면서 희망의 줄기를 품게 되었다.

전문재활병원 뇌졸중 환자를 돌보는 가족 돌봄 제공자들의 삶의 부정적 변화는 비울 수 없는 자리, 반복되는 일상으로 인한 '쳇바퀴에 갇힌 인생'과 외적 미의 포기, 사회생활의 제한, 신체 증 상의 고통으로 인한 '잃어버린 나 자신'을 경험하였다. 이는 입원 중인 뇌졸중 환자의 상주 돌봄 요구의 증가, 일상 활동 제한 등으로 돌봄 제공자의 어려움이 더 큰 것으로 나타난 선행 연구의 결과와 유사했다[10][14]. 뇌졸중 환자의 가족 돌봄 제공자의 돌봄은 환자의 유병기간이 증가함에 따라 신체적 건강 상태를 비롯해 심리적 건강 상태의 적신호도 함께 발생하게 된다[9]. 이로 인해 신체 증상의 고통을 경험하며, 이는 대상자들의 돌봄 경험의 본질을 통해 도출된 삶의 부정적 변 화를 경험한다는 결과를 뒷받침하는 근거임을 알 수 있다. 뇌졸중 환자를 돌보는 가족 돌봄 제공 자들은 환자와 더불어 자신의 일상에 큰 변화를 경험하면서 삶에 대한 부정적인 감정을 느끼는 것 으로 나타났으므로 그들의 현실적인 어려움을 예측해야 하며, 가족 돌봄 제공자 개인의 삶의 일부 를 영위할 수 있도록 자원봉사, 건강관리 지원 서비스 프로그램 제공 등의 현실적 중재 전략들에 대한 접근이 필요할 것으로 사료된다.

대상자들이 경험한 돌봄 부담은 부족한 전문적 기술, 부족한 도움, 공동생활로 인한 '현실적 돌 봄 부담감이었고, 지쳐가는 마음, 어두운 미래의 절망감으로 인한 '심리적 돌봄 부담감이었다. 이 는 뇌졸중 환자를 돌보는 가족 돌봄 제공자가 경제 상태 및 시간 소요 등의 부담감, 부양 스트레 스를 경험한다는 선행 연구[15]와 일치한다. 따라서 주 돌봄 제공자들이 환자를 돌보는 데 있어 전 문적인 돌봄 기술 교육, 바우처 연계 서비스와 같은 경제적 지원, 병원 내 휴식공간 제공 등의 지 원이 필요하다. 또한, 계속되는 스트레스 상황을 극복할 수 있도록 내적 심리자원 향상을 위한 긍 정심리 기반의 코칭 프로그램 제공이 필요하다. 이에 돌봄 부담감을 감소시킬 수 있는 다차원적인 제도를 적극적으로 마련하고, 실현하는 것이 요구된다.

대상자들은 환자와 함께한 추억, 환자에 대한 책임감, 환자와의 교감을 통해 '환자로 향하는 마 음'을 경험했으며, 가족의 사랑, 신앙의 믿음, 새로운 삶의 목표를 가지고 '희망의 동기'를 통해 긍 정적으로 변화하여 '희망의 줄기'를 경험하였다. 이와 관련된 선행연구는 뇌졸중 환자 가족의 돌봄 
경험은 심리적 충격, 헤어날 수 없는 절망감, 제도권에 대한 야속함, 심리적 갈등의 부정적 측면과 의지하고 싶은 욕구, 다행스러워하는 마음, 소망을 갖는 마음의 긍정적 측면의 핵심 범주를 보고하 였다[16]. 본 연구의 결과에서도 가족 돌봄 제공자는 시련에 부딪혔지만, 회복을 위한 '희망'에 열 중하는 공통적인 특징을 보였다. 가족 돌봄 제공자가 힘든 상황에서 희망을 품기 위해서는 환자와 가족 돌봄 제공자 간의 유대감이 중요하다는 것을 확인할 수 있었다. 이에 의사소통 향상 프로그 램을 제공하여 유대감을 강화할 기회가 제공되어야 한다. 또한, 가족 돌봄 제공자의 정서적 힘이 되어주는 가족의 참여와 영적 안녕을 향상할 수 있는 종교적 지지가 요구된다. 그리고 뇌졸중 환 자의 가족 돌봄 제공자가 희망을 통하여 스스로 돌봄 과정을 긍정적으로 극복할 수 있도록 해야 한다.

본 연구는 뇌졸중 환자 가족 돌봄 제공자의 삶의 부정적 변화, 돌봄 부담감, 희망의 줄기에 관 해 새로운 구성요소를 도출하였다. 도출된 요소들은 뇌졸중 환자 가족 돌봄 제공자를 위한 중재 프로그램 개발 및 효과 검증을 위한 근거자료로 활용할 수 있을 것이다.

\section{5. 결론 및 제언}

재활전문병원 뇌졸중 환자 가족 돌봄 제공자들의 돌봄 경험을 이해하고 돌봄에 대한 본질에 영향 을 미치는 요소를 파악하기 위해 현상학적 연구 방법을 사용하였다. 연구 결과 쳇바퀴에 갇힌 인 생', ‘잃어버린 나 자신', '현실적 돌봄 부담감' '심리적 돌봄 부담감, '환자로 향하는 마음', '희망의 동기' 여섯 가지 구성요소를 도출하였다. 대상자들은 삶의 부정적 변화, 돌봄 부담감을 경험하였지 만, 긍정적 구성요소를 통해 희망의 줄기를 표현하였다. 대상자들의 돌봄 경험을 현상학적 연구를 통해 파악함으로써 대상자들의 돌봄 과정에서 긍정적인 내면을 확인할 수 있었고, 심리·정서적인 긍정의 변화를 위해 노력할 수 있는 계기가 마련되었다고 볼 수 있을 것이다.

도출된 돌봄 경험의 구성요소는 뇌졸중 환자 가족 돌봄 제공자를 위한 중재의 방향성을 제시하 기 위해 활용될 수 있을 것이다. 따라서 돌봄 경험의 본질을 탐색한 결과를 토대로 대상자들의 희 망을 강화하고, 돌봄 부담감을 감소시켜야 한다. 또한, 전문 의료진과의 친밀함을 통해 돌봄 과정 에서 필요한 지식과 기술적인 측면을 습득함으로써, 현실적 돌봄 부담감이 감소할 수 있는 정책적 제안과 교육 프로그램 제공이 필요할 것이다.

본 연구는 돌봄 경험에 관한 현상학적 연구로서, 경험에 대한 적절성이 충족되는 대상자만 인터 뷰를 진행하였다. 개인의 과거와 현재 경험에 대한 인터뷰에서 대상자의 기억력에 의존할 수밖에 없었다는 제한점이 있다. 그러나 환자 돌봄 경험을 가장 잘 파악할 수 있는 가족을 대상으로 돌봄 과정의 의미와 본질을 파악함에 의의가 있다고 사료된다. 향후 연구에서는 더욱 심도가 있는 돌봄 경험을 이해하기 위해 가족 돌봄 제공자들과 그 외 돌봄 제공자들의 돌봄 어려움을 극복한 경험 과 극복하지 못한 경험 후 삶의 변화를 분석하는 연구가 이루어져야 할 것이다.

본 연구는 재활전문병원에 입원한 뇌졸중 환자의 가족 돌봄 제공자들의 돌봄 경험을 통한 부정 
적인 측면 이외에 긍정적인 측면의 개념이 새롭게 도출되었다는 점에서 연구의 의의가 있으며, 향 후 연구에서는 이러한 측면을 반영한 프로그램 개발과 다차원적 제도 마련이 필요할 것으로 제언 한다.

\section{References}

[1] Korean Statistics Information Service, Views on elderly patients' care, Deajeon, Statistics Korea, (2014)

[2] I. J. Kim, Sources of Anxiety and Burden of Family Caregivers of Stroke Patients: The Role of Self-efficacy and Knowledge about Care, Korean Journal of Adult Nursing, (2012), Vol.24, No.1, pp.1-10, UCI: G704-000678.2012.24.1.005

[3] Y. J. Jo, M. S. Hyun, J. H. Park, Effects of Self-efficacy and Social Support on Health Promotion Behaviors of Patients with Stroke, The Journal of Muscle and Joint Health, (2019), Vol.26, No.3, pp.167-174, DOI: 10.5953/JMJH.2019.26.3.167

[4] H. Y. Lee, S. G. Bong, The Effect of Home Based Rehabilitation Program on Activities of Daily Living, Self-efficacy, Quality of Life Among Chronic Stroke Patients, Journal of Special Education \& Rehabilitation Science, (2015), Vol.54, No.3, pp.275-291, DOI: 10.15870/jsers.2015.09.54.3.275

[5] H. Y. So, J. W. Kim, J. W. Park, N. Y. Lim, Task Analysis of the Job Description of Rehabilitation Nurse based on DACUM, Korean Journal of Rehabilitation Nursing, (2009), Vol.12, No.1, pp.16-29, UCI: G704-SER000001296.2009.12.1.001

[6] B. M. Mun, Y. S. Lee, B. H. Lee, The relationship between the patient's health beliefs and the implementation of functional movement rehabilitation and ability to perform ADL in stroke patients, Journal of the Korea Academia-Industrial cooperation Society, (2012), Vol.13, No.7, pp.3057-3064, DOI: 10.5762/KAIS.2012.13.7.3057

[7] Views on elderly patients' care, Korean Statistics Information Service, (2014)

[8] J. S. Lim, B. Y. Chung, Influencing Factors on the Family Caregivers' Burden of Inpatients with Acute Stroke, The Journal of Korean Academic Society of Nursing Education, (2018), Vol.24, No.2, pp.149-159, DOI: http://dx.doi.org/10.5977/jkasne.2018.24.2.149

[9] E. C. Ursula, Spousal caregiving for stroke survivors, Journal of Neuroscience Nursing, (2007), Vol.39, No.2, pp.112-119, DOI: 10.1097/01376517-200704000-00008

[10] N. H. Kim, Y. S. Tae, Y. S. Choi, J. H. Bae, Influencing Factors on Stress in Caregivers of Stroke Patients Being Admitted in Rehabilitation Centers, Journal of Korea Academia-Industrial cooperation Society, (2016), Vol.17, No.2, pp.188-201, DOI: http://dx.doi.org/10.5762/KAIS.2016.17.2.188

[11] Guiding principles for the development of a navigation model to support transitions to the community for persons with stroke and their families, Ontario Stroke Network, (2014)

[12] J. Millar, T. Readman, W. Johnstone, Community stroke recovery navigator program phase 2: helping stroke survivors and family caregivers from hospital to long term recovery developed by, Stroke Recovery Association, (2015) 
[13] P. F. Collaizzi, Psychological reseach as the Phenomenogist Views It, Existential-phenomenological Alternatives for Psychology, Oxford University Press, (1978), pp.48-71.

[14] S. H. Baek, E. J. Park, M. S. Cho, H. Y. Kim, Analysis of the Burden Factors Influencing Quality of Life of Stroke Patients Caregivers, Jouranl of the Korea Entertainment Industry Association, (2016), Vol.10, No.5, pp.227-234, DOI: $10.21184 /$ jkeia.2016.10.10.5.227

[15] J. W. Lee, Y. K. Kim, Correlation between Quality of Life and Stress of Caregivers who Support Elderly with Percutaneous Endoscopic Gastrostomy (PEG), Journal of the Korean Data Analysis Society, (2013), Vol.15, No.2, pp.841-858, UCI: G704-000930.2013.15.2.044

[16] Lee K. R., (The) caring lived experience of the adulthood stroke, Department of Nursing The Graduate School of Kyung-Hee University, Master's thesis, (2001) 